\title{
Study on the Impact of Polymer Retention in Porous Media on Further Surfactant-Polymer Flood
}

\author{
Junjian Li*, Hanqiao Jiang, Qun Yu, Fan Liu and Hongxia Liu \\ College of Petroleum Engineering, China University of Petroleum, Beijing, P. R. China
}

\begin{abstract}
Polymer flood gains expansive popularity as a promising EOR method in various oilfields worldwide. However, there are still substantial amount of resources underground after polymer application. To further enhance oil recovery, secondary chemicals are sometimes utilized to sweep the remaining hydrocarbons to maintain the consistent development of oilfields. In this paper, a series of experiments are established and conducted to explore the feasibility of surfactant/polymer flooding applied to a polymer flooded reservoir, and also the influence of polymer retention in porous media to enhance the oil recovery performance of subsequent chemical drive. The data of the experiments suggest that surfactant/polymer flooding owns a very good potential as a subsequent EOR technique, and that polymer retention in pores helps block underground water channels, improving greatly the sweeping efficiency of secondary chemical flood.
\end{abstract}

Keywords: Further EOR, polymer retention, polymer/surfactant flood.

\section{INTRODUCTION}

Polymer flood can effectively enhance oil recovery by improving sweeping and flooding efficiency, making it a promising and widely-applied EOR method both at home and abroad. In some oilfields in China, polymer flood can enhance oil recovery up to nearly $14 \%$ of the original oil in place [1]. In spite of the remarkable performance of polymers, there are still substantial amount of reserves, nearly half of original oil in place, in porous media after polymer flood [2]. To excavate these remaining hydrocarbons and keep the consistent development of oilfield, secondary chemicals are frequently taken into consideration to further enhance oil recovery, such as surfactant and polymer.

Surfactant/polymer flood (SP) is a binary combination flooding method integrating the benefits of both polymer flood and surfactant flood. It originally derives from alkalisurfactant-polymer flooding technique (ASP) and excludes the existence of alkali, without derogating too much the comprehensive EOR advances of the combination drive [3]. In particular, surfactant/polymer flood avoids a lot of problems and troubles that alkali could bring about, such as scaling and fluid emulsification, demonstrating a very big EOR potential.

To the massive valuable remains after polymer application, some scholars had discussed the further enhanced oil recovery technique succeeding polymer flooding [4], Lu Xiangguo [5] conducted experimental study to further improve recovery method after polymer flooding, and proposed that injecting higher molecular weight, greater concentration of the polymer or cross linked polymer can further expand the swept volume and enhance oil recovery in the

*Address correspondence to this author at the College of Petroleum Engineering, China University of Petroleum (Beijing), Beijing, P. R. China; Tel: +860189732163; Fax: +860189732163;

E-mail: 1ijunjian@foxmail.com embodiment of reservoir after a polymer flooding. Guo Shangping [4] further explored enhanced oil recovery problem after polymer flooding, and proposed the surfactant flooding after polymer flooding and the liquid crystal system flooding after polymer flooding. Then Liu Ye, Zhao Fulin, Li Aifen and other people also proposed a lot of further improving recovery methods after polymer flooding [6-18], such as the microbial flooding after polymer flooding, the profile control agent deep profile after polymer flooding, the foam flooding after polymer flooding and other methods. All the experimental studies have shown that using appropriate methods after polymer flooding can further enhance oil recovery. But they failed to cover SP flooding, and discuss the influence of polymer retention on subsequent EOR technique. In this work, a series of experiments are initiated to investigate the feasibility of subsequent surfactant/polymer flood applies to remains after first EOR application of polymer flooding. In addition, the influence of polymer retention in porous media on the performance of later chemical drive is also discussed.

\section{MODEL DESIGN}

For simplicity and representativeness, a typical twodimension (2D) double-layer model with a size of $30 \times 4.5 \times 4.5 \mathrm{~cm}$ is established (shown in Fig. 1). To take into consideration and the heterogeneity, the permeability of two layers is specified as $800 \mathrm{mD}$ and $200 \mathrm{mD}$ respectively, the porosity of the two layers is about $23 \%$.

\section{EXISTING FORMS OF THE POLYMER IN FORMA- TION AFTER POLYMER FLOODING}

Because of the size of polymer molecule, there is an inaccessible pore volume for polymer in the formation as naturally polymers do not exist in the space. But in accessible pore volume, the residual polymer exists in the forms of dissolution, absorption and entrapment. The retention quantity 
of residual polymer includes the absorption quantity on the surface of sandstone and entrapment quantity in the pore.

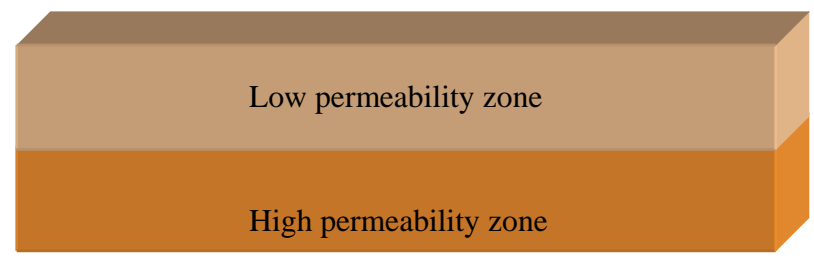

Fig. (1). The two-layer 2D model.

The material balance method is used to determine retention quantity of polymer in formation. The steps are as follows: 1) Inject $0.57 \mathrm{PV}$ polymer solutions with a concentration of $1000 \mathrm{mg} / \mathrm{L}$ to the core; 2) Inject $0,0.2,0.4,0.6$ and $1.0 \mathrm{PV}$ volumes of water to the core respectively after polymer injection; 3) Measure produced concentration of polymer at the deliver end; 4) Calculate the retention quantity of polymer in the core according to equation (1):

$Q=\left(\rho_{0} V_{0}-\sum_{i=1}^{n} \rho_{i} V_{i}\right) / W$

Where:

$Q$ - the retention quantity of HPAM, $\mu \mathrm{g} \cdot \mathrm{g}^{-1}$;

$\rho_{0}$ - the mass concentration of HPAM, $\mathrm{mg} \cdot \mathrm{L}^{-1}$;

$V_{0}$-accumulative injection volume of HPAM, $\mathrm{mL}$;

$\rho_{i}-$ mass concentration of the i sample of effluent HPAM, $\mathrm{mg} \cdot \mathrm{L}^{-1}$

$V_{i}$ - the volume of the i sample of effluent HPAM, mL;

$n$ - the number of effluent HPAM sample;

$W$-dry weight of core, $g$ 。

If the wettability of the core altered from water-wet to oil-wet by steeping in the silicone oil, it can eliminate the absorption of polymer in the core. Thus the entrapment is equals to retention of HPAM.

From Table 1 we can see that the retention quantity of HPAM in the core is about 2.5 times compared to the entrapment quantity in the core. The absorption quantity of polymer in the core equals to the difference of the retention quantity and the entrapment quantity, which is generated by dynamic absorption.

Table 1. Polymer remnant of different models.

\begin{tabular}{|c|c|c|c|c|}
\hline No. & $\begin{array}{c}\text { Porosity } \\
\text { (\%) }\end{array}$ & $\begin{array}{c}\text { Polymer } \\
\text { remnant } \\
\text { (mg) }\end{array}$ & $\begin{array}{c}\text { Polymer } \\
\text { entrapment } \\
\text { (mg) }\end{array}$ & $\begin{array}{c}\text { Polymer } \\
\text { adsorption } \\
\text { (mg) }\end{array}$ \\
\hline \hline 1 & 23.64 & 35.1 & 13.5 & 21.6 \\
2 & 23.54 & 18.4 & 7.7 & 10.7 \\
3 & 23.85 & 15.6 & 6.2 & 9.4 \\
4 & 24.07 & 13.9 & 5.5 & 8.4 \\
5 & 23.18 & 12.2 & 4.7 & 7.5 \\
\hline
\end{tabular}

To calculate the dissolution quantity of polymer in the core, we assume that the core was $1 \mathrm{~m}^{3}$, the porosity was
$30 \%$, inaccessible volume was $10 \%$, the mass concentration of injected polymer was $1750 \mathrm{mg} \cdot \mathrm{L}^{-1}$, the density of sandstone was $2.6 \mathrm{t} \cdot \mathrm{m}^{-3}$, the produced polymer mass occupied about $10 \%$ of the injected polymer. Then the calculated results are that in about $90 \%$ of the residual polymer, the dissolution quantity, the absorption quantity and the entrapment quantity separately account for $79 \%, 6 \%$ and $5 \%$ of the injected polymer.

\section{ABSORPTION QUANTITY DETERMINATION OF THE SURFACTANT AFTER POLYMER FLOODING}

To accurately analyze the rule of adsorption and retention of surfactant in porous media, the experiment investigated the dynamic adsorption and retention law of surfactant solution in the core without oil, and concentrations of the surfactant solution were separately $0.1 \%, 0.2 \%, 0.3 \%, 0.4 \%$. Retention quantity means the amount of active agent existing in the unit weight (or volume) core after the active agent solution flow through the core, and the total retention quantity equals to the difference in the total amount of active agent injected into the core and the total amount of active agent flowing out of the core. In another set of experiment, we separately injected surfactant solution with concentration $0.1 \%, 0.2 \%, 0.3 \%, 0.4 \%$ under the conditions of different residual polymer after polymer flooding, and then analyze its dynamic adsorption and retention law under the existence of residual polymer. The injection rate was $0.5 \mathrm{~mL} / \mathrm{min}$.

The adsorption quantity gradually increased with the increase in surfactant concentration in the cores with residual polymer (Table 2), when surfactant concentration is $0.3 \%$, the adsorption quantity reached the maximum of $0.378 \mathrm{mg} / \mathrm{g}$, and then with the increase in surfactant concentration, the adsorption quantity decreased, which indicates that the dynamic adsorption number of the surfactant with $0.3 \%$ concentration reaches to a peak. With the increase in polymer residues, the adsorption quantity of the surfactant is further reduced. The solubility of the surfactant is limited, when the solubility reaches the maximum, the absorption quantity reaches maximum of $0.378 \mathrm{mg} / \mathrm{g}$. The adsorption number occurs in the vicinity of the critical micelle concentration (CMC), as surfactant concentration is $0.3 \%$, and then the adsorption number declined with the increase in surfactant concentration. The existence of the polymer reduces the adsorption of surfactants. The adsorption quantity of low concentration surfactant in the solid surface is large, and it will gradually decrease with the increase of surfactant concentration.

Since the structure of polymer and surfactant molecule are different, clay minerals in the core of their adsorption capacity have differences, and thus the competitive adsorption between surfactant and the polymer molecules in rock surface occures, which greatly reduces transient absorption quantity of the surfactant agent in the flowing channels of the system, the surfactant cannot be out of the system and alone enter inaccessible pore volume of the polymer, so it further decreases the adsorption of surfactant in the rock and reduces the loss of surfactant adsorption. For the above reasons, the adsorption loss of surfactant under the conditions of residual surfactant will greatly lower the adsorption quantity under the conditions of no polymer. 
Table 2. Surfactant adsorption quantity under the conditions of different residual polymer.

\begin{tabular}{|c|c|c|c|c|}
\hline No. & $\begin{array}{c}\text { Porosity } \\
(\%)\end{array}$ & $\begin{array}{c}\text { Polymer } \\
\text { Retention } \\
(\mathrm{mg} / \mathrm{g})\end{array}$ & $\begin{array}{c}\text { Surfactant } \\
\text { concetration,\% } \\
(\mathrm{mg} / \mathrm{L})\end{array}$ & $\begin{array}{c}\text { Surfactant } \\
\text { Adsorption } \\
\text { (mg/g) }\end{array}$ \\
\hline $\begin{array}{c}9 \\
10 \\
11 \\
12\end{array}$ & $\begin{array}{l}23.89 \\
23.27 \\
24.12 \\
23.42\end{array}$ & 18.4 & $\begin{array}{l}0.1 \\
0.2 \\
0.3 \\
0.4\end{array}$ & $\begin{array}{l}0.023 \\
0.088 \\
0.166 \\
0.157\end{array}$ \\
\hline
\end{tabular}

Table 3. Experimental procedure.

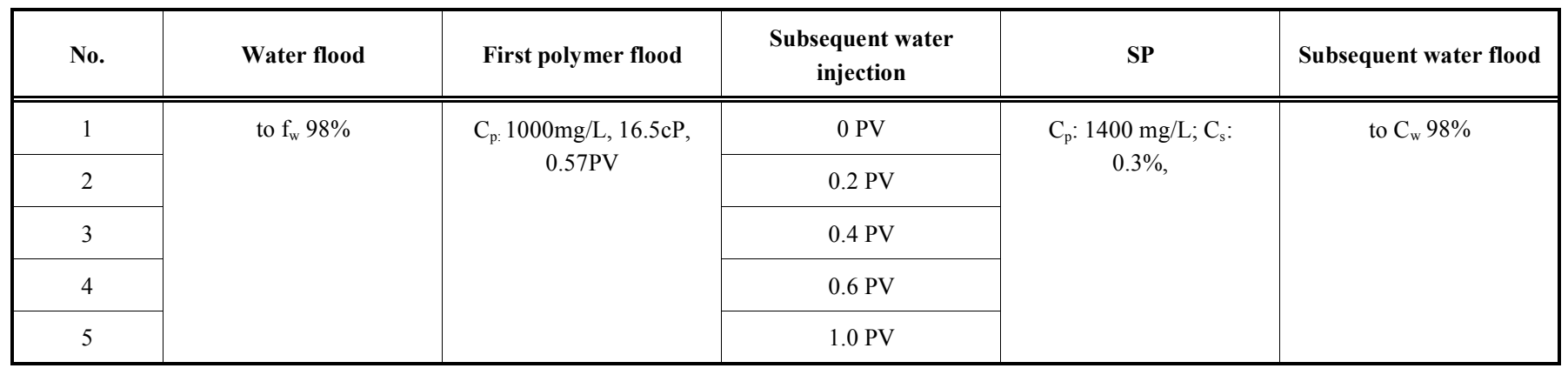

Table 4. Experimental outcomes for all models.

\begin{tabular}{|c|c|c|c|c|c|c|c|}
\hline No. & $\begin{array}{c}\text { Porosity } \\
(\%)\end{array}$ & $\begin{array}{c}\mathbf{S}_{\mathbf{0}} \\
\mathbf{( \% )}\end{array}$ & $\begin{array}{c}\text { Water recovery } \\
(\mathbf{\%})\end{array}$ & $\begin{array}{c}\text { Water slug } \\
(\mathbf{P V})\end{array}$ & $\begin{array}{c}\text { Polymer } \\
\text { recovery (\%) }\end{array}$ & $\begin{array}{c}\text { SP recovery } \\
\text { increment (\%) }\end{array}$ & $\begin{array}{c}\text { Ultimate } \\
\text { recovery (\%) }\end{array}$ \\
\hline \hline 1 & 23.64 & 73.34 & 47.09 & 0 & 65.38 & 10.06 & 75.43 \\
\hline 2 & 23.54 & 73.55 & 47.87 & 0.2 & 65.24 & 8.45 & 73.69 \\
\hline 3 & 23.85 & 74.78 & 46.31 & 0.4 & 66.09 & 7.25 & 73.34 \\
\hline 4 & 24.07 & 73.92 & 46.74 & 0.6 & 66.75 & 6.53 & 73.28 \\
\hline 5 & 23.18 & 74.16 & 45.95 & 1.0 & 67.38 & 6.21 & 73.59 \\
\hline
\end{tabular}

\section{OIL DISPLACEMENT OF IMPACT OF POLYMER RETENTION ON SP FLOOD}

To make a comparison, 5 of these models are prepared with nearly the same properties. The porosity of these models is approximately $23.6 \%$. Saturate these models with crude oil, and expose them to air over several days for sufficient interaction between oil and soil. Flood models with water to a water cut of $98 \%$. The injection rate was $0.5 \mathrm{~mL} / \mathrm{min}$. Then $0.57 \mathrm{PV}$ polymer solutions with a concen- tration of $1000 \mathrm{mg} / \mathrm{L}$, sheared viscosity of $16.5 \mathrm{cP}$ are injected to each model for the first EOR application. Afterwards, 0, $0.2,0.4,0.6$ and 1.0 PV volumes of water are utilized to sweep each model respectively after polymer injection, making distinct polymers exist in these models. Finally surfactant/polymer flooding technique is applied to each model until water cut reaches $98 \%$ for further enhanced oil recovery process. During the entire processes, water cut is observed and oil recovery is gauged Table $\mathbf{3}$. 


\section{ANALYSIS OF THE RESULTS}

There could be approximately equivalent amount of polymers retained in each model mainly due to adsorption and retention after injecting $0.57 \mathrm{PV}$ polymer solutions. To differentiate the dimension of polymer retention in each model before surfactant/polymer application, different volumes of water are injected to sweep these models.

The outcome of the experiments in Table $\mathbf{4}$ suggests that the amount of polymer retention in porous media plays an important role in the enhanced oil recovery performance of later polymer-surfactant drive. It shows apparently in Table 1 that the bigger the size of water slug used to sweep the model after polymer injection, the fewer polymers retain in the porous media, and the worse the performance of polymer-surfactant flood.

Some data are presented in curves, just as shown in Figs. $(2,3)$. It has been demonstrated in Fig. (2) that polymer retention retained in porous media plays a positive role in the recovery of subsequent surfactant-polymer flood. In reality, polymers retained in formations help block some big channels and hence advance the sweeping area of subsequent chemical drive. In mechanism, therefore, the more polymers retained in porous media, the bigger the sweeping zone and the better the chemicals flood.

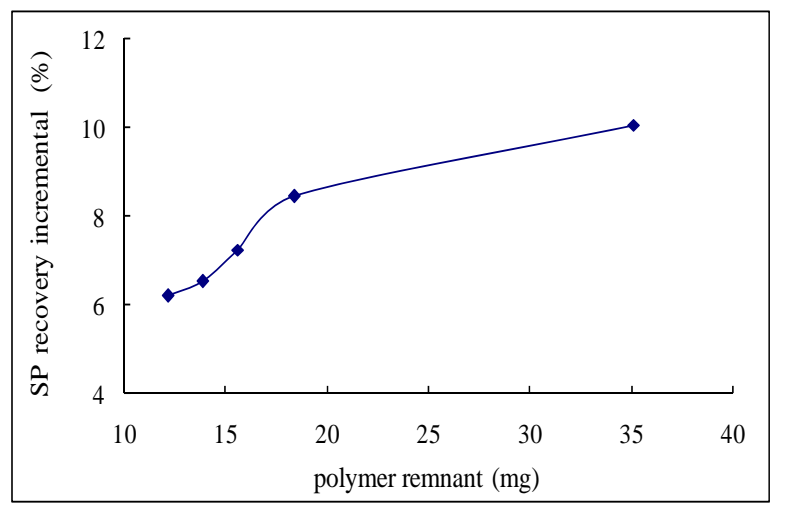

Fig. (2). The influence of polymer retention to SP EOR effect.

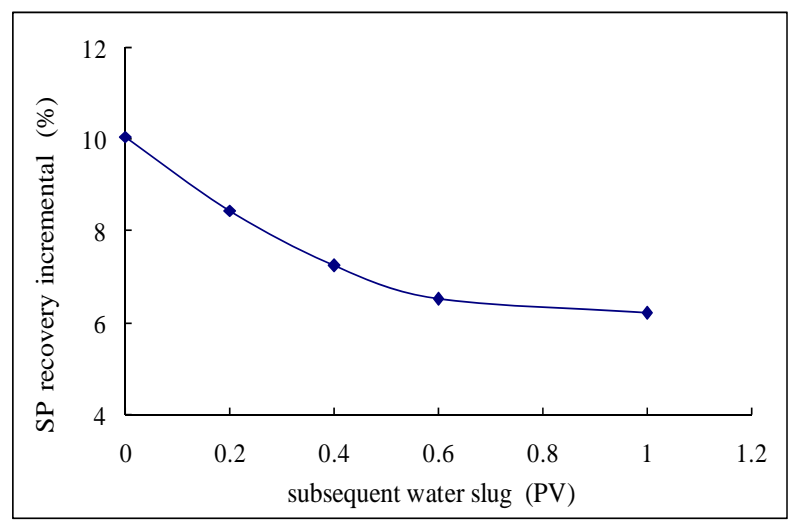

Fig. (3). The influence of the size of subsequent water slug to SP EOR effect.

Fig. (3) reveals the relationship between the recovery of subsequent chemicals drive and the water injection after polymer flood. Water slugs sweep polymers in porous me- dia, making polymers retain in pores at different levels. So more water sweeps out more polymers, lowering the amounts of polymers retained in pores and consequently minimizing the EOR effect of subsequent surfactant-polymer flood.

More accurately, we find out from the curve in Fig. (3) that when subsequent water slug exceeds $0.4 \mathrm{PV}$, the polymer-surfactant recovery increases very smoothly, indicating that polymer adsorption and desorption, in this circumstance, reaches a state of equilibrium and no more polymer could be flooded out by water.

Curves describing oil recovery incremental and water cut for each model follow as shown from Figs. (4-8).

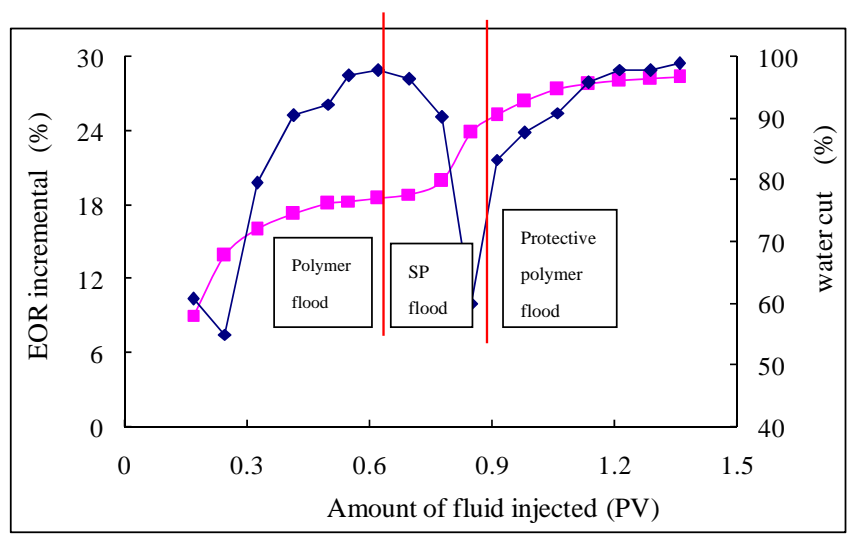

Fig. (4). Oil recovery incremental and water cut for Case 1.

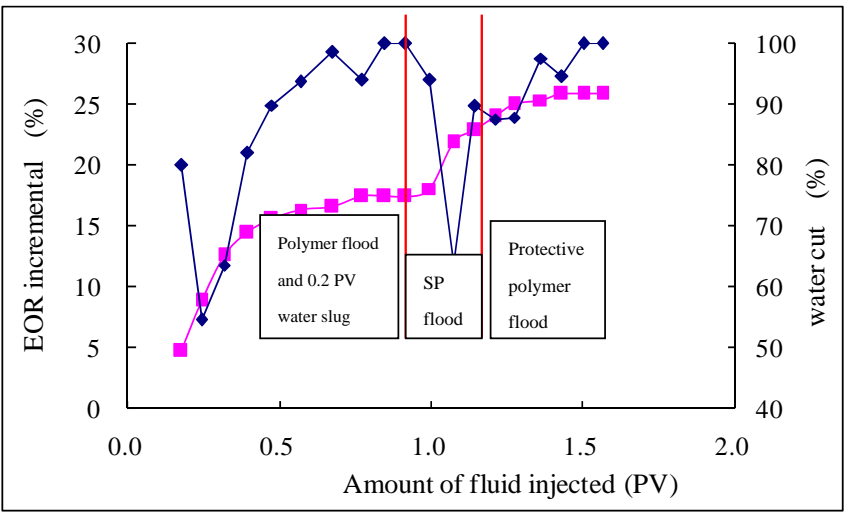

Fig. (5). Oil recovery incremental and water cut for Case 2.

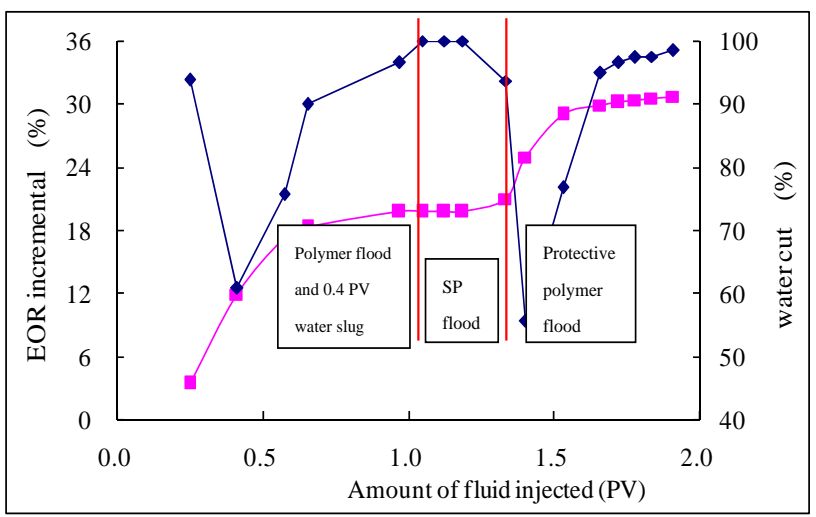

Fig. (6). Oil recovery incremental and water cut for Case 3. 


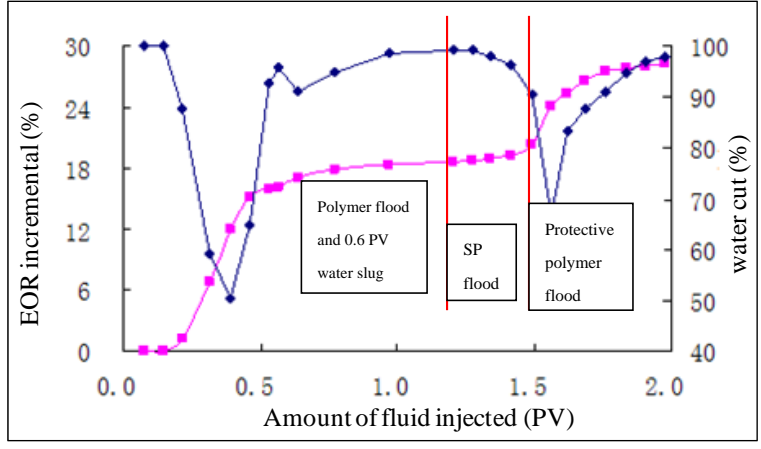

Fig. (7). Oil recovery incremental and water cut for Case 4.

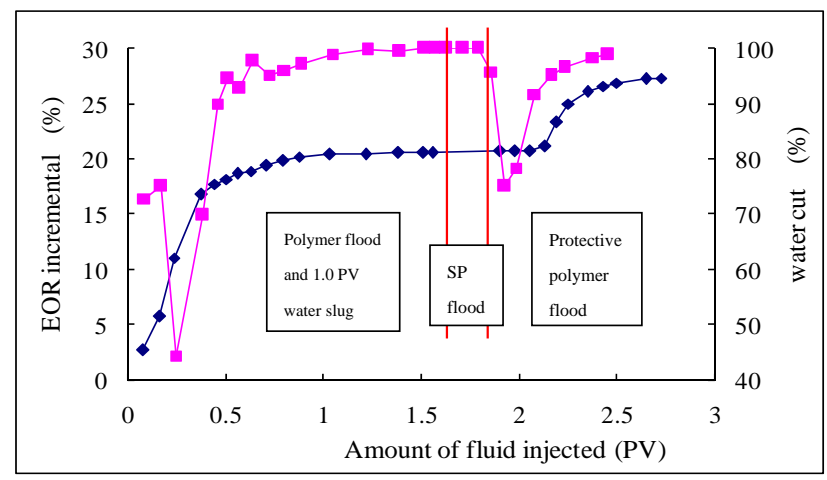

Fig. (8). Oil recovery incremental and water cut for Case 5.

In these curves, we can clearly observe that two water cut troughs exist during this entire experimental procedure. One is at the first polymer flood, exhibiting polymer's remarkable water control mechanism, while the other is at the surfactantpolymer combination flood, demonstrating SP's promising prospective as a further EOR approach after first polymer flood. As for oil recovery, it appears that a bigger water slug after first polymer injection accounts for a better EOR performance of the subsequent SP flood. And the highest and lowest recovery incrementals from SP application are $10.06 \%$ and $6.21 \%$ respectively, with a big difference of 3.85 percentage which reveals greatly the important role of polymer remnant in porous media in further EOR method.

Figs. $(9,10)$ compare the oil recovery incremental and water cut of these models comprehensively.

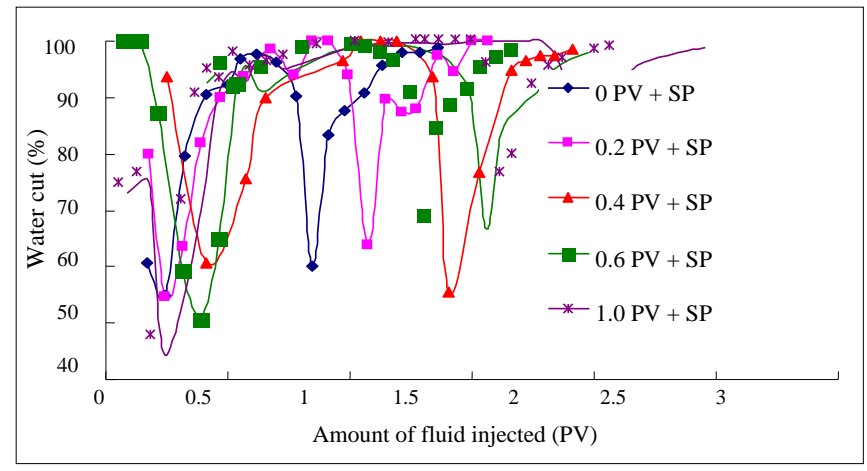

Fig. (9). Water cut for all cases.

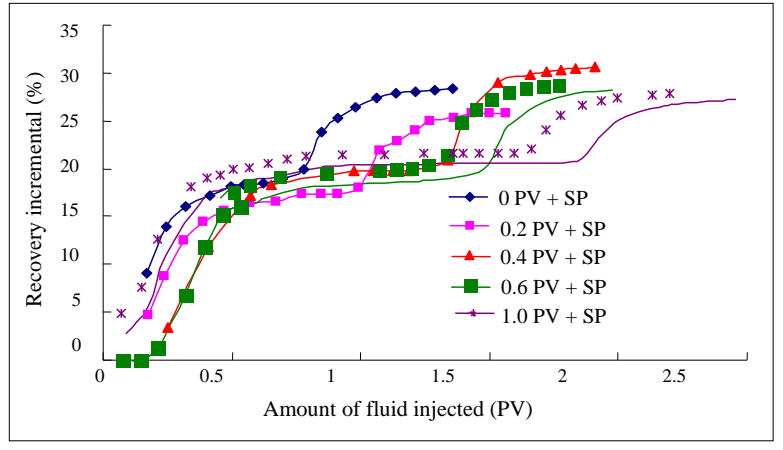

Fig. (10). Oil recovery incremental for all cases.

\section{CONCLUSION}

1. Polymer flood served as a strong EOR technique can produce remarkable amount of oil. Reserves in pores, however, are still substantial and worth investigating. Further EOR technique is of significant importance.

2. Surfactant-polymer flood is a promising EOR method, and can serve as a favorable subsequent EOR technique applying to oilfields undergoing polymer injection. Experiments exhibit that surfactant-polymer application after polymer flood can attribute to up to $10 \%$ OOIP at most in recovery incremental, demonstrating a very big further EOR potential.

3. Polymer remnant in pores plays a significant role in the subsequent surfactant-polymer flood. Experiments show that polymers retained in porous media can block big channels and hence improve sweep efficiency, guaranteeing a better EOR performance of further chemicals combination drive. In particular, the positive role of polymer remnant to further improve EOR performance can reach to constant when polymers go into a state of equilibrium of adsorption and desorption.

\section{CONFLICT OF INTEREST}

The authors confirm that this article content has no conflict of interest.

\section{ACKNOWLEDGEMENTS}

Declared none.

\section{REFERENCES}

[1] H.L. Chang, Z.Q. Zhang, Q.M. Wang and Z.S. Xu, "Advances in polymer flooding and alkaline-surfactant-polymer processes as developed and applied in the Peoples Republic of China", in Society of Petroleum Engineers Paper SPE 89175, pp. 84-89, 2006.

[2] X.G. Lu, F.L. Wang and Y.C. Bao, "The effectiveness of asp flood in polymer flooded reservoirs of Daqing", Oilfield Chemistry, vol. 17, pp. 159-164, June 2000.

[3] X. Lv, J. Zhang and W. Jiang, "Advances in polymer/surfactant binary combination drive", Journal of South West Petroleum University (Science\& Technology Edition), vol. 30, pp. 85-87, Jun 2008.

[4] S.P. Guo, G.L. Tian, F. Wang, Q.H. Lei and C. Tao, "The problem of quaternary oil recovery ducceeding a polymer flooding", Acta Petrolei Sinica, vol. 18, pp. 49-53, October 1997. 
[5] G.A. Pope, B. Wang, and T. Kerming, "A sensitivity study of micellar/polymer flooding”, SPE Journal, vol. 19, no. 6, pp. 357-368, 1979.

[6] A.F. Li, H. Chen, and J. Tao, "Feasibility of water shut-off using cationic polymer for reservoir displaced by polymer", Acta Petrolei Sinica, vol. 27, pp. 45-48, February 2003.

[7] M. Shi, "Feasibility of MEOR after polymer flooding", Petroleum Geology \& Oilfield Development in Daqing, vol. 23, pp. 56-58, April 2004.

[8] F.L. Zhao, Y.F. Wang, and C.L. Zhao, "Techniques of enhanced oil recovery after polymer flooding", Acta Petrolei Sinica, vol. 30, pp. 86-89, February 2006.

[9] W.T. Ostertloh and M.J. Janter Jr, "Effects of gas and liquid velocity on steady-state foam flow at high temperature", SPE/DOE Enhanced Oil Recovery Symposium, 1992, pp. 237-248.

[10] R.D. Sydansk, and Marathon oilco, "Polymer-enhanced foams part 2: propagation through high-permeability sandpacks", SPE $A d$ vanced Technology Series, 1993, pp. 245-254.

[11] S.R. Sun, X.H. He, and X. Wu, "Laboratory evaluation of remaining oil distribution by NMR technology after polymer flooding", Petroleum Geology \& Oilfield Development in Daqing, vol. 22, pp. 61-63, August 2003.
[12] P.H. Han, Q. Zhao, and S.S. Mu, "Study on further EOR after polymer flooding", Petroleum Geology \& Oilfield Development in Daqing, vol. 25, pp. 81-84, October 2006.

[13] G. Wang, D.M. Wang, and H.F. Xia, "Mechanism for enhancing oil-displacement efficiency by beraine surfactant after polymer flooding”, Acta Petrolei Sinica, vol. 28, pp. 86-90, July 2007.

[14] T. Xu, X.S. Li, and X.H. Zhang, "Parallel-column experiments for enhancing oil recovery after polymer flooding", Petroleum Exploration and Development, vol. 31, pp. 98-100, December 2004.

[15] S.C. Xiong,Y.F. Wang, and Y. He, "The study on EOR after Polymer flooding of Gudao Oilfield", Fault-Block Oil \& Gas Field, vol. 12, pp. 38-40, May 2005.

[16] D.H. Guo, H.C. Xin, and X.D. Cui, "Study on enhanced oil recovery by using OCS surfactant/polymer binary system after polymer flooding", Advances in Fine Petrochemicals, vol. 7, pp. 1-3, January 2006.

[17] H. Liu, "Current situation and prospect for oil recovery techniques after polymer flooding in Daqing Oilfield", Oil Drilling \& Production Technology, vol. 30, pp. 1-6, June 2008.

[18] H.F. Xia, D.M. Wang, and Z.C. Liu, "Study on the mechanism of polymer solution with visco-elastic behavior increasing microscopic oil displacement efficiency", Acta Petrolei Sinica, vol. 22, pp. 60-65, July 2001.

Received: September 15, 2014

Revised: January 19, 2015

Accepted: February 04, 2015

(C) Li et al.; Licensee Bentham Open.

This is an open access article licensed under the terms of the Creative Commons Attribution Non-Commercial License (http://creativecommons.org/licenses/by-nc/3.0/) which permits unrestricted, non-commercial use, distribution and reproduction in any medium, provided the work is properly cited. 